\title{
ENHANCEMENT OF THE PERFORMANCE OF A TRANSFER FIELD ELECTRIC MACHINE OPERATING IN THE ASYNCHRONOUS MODE
}

\author{
E. S. Obe ${ }^{1,{ }^{*}}$ and L. U. Anih ${ }^{2}$ \\ 1,2 Department of Electrical EngineERING, UNiversity of Nigeria, NSUKKA. ENUGU STATE - NigERIA \\ E-mail addresses: ${ }^{1}$ simon.obe@unn.edu.ng,2linus.anih@unn.edu.ng
}

\begin{abstract}
This paper reports the enhancement of the output power and power factor of a transfer field machine operating in the asynchronous mode by direct capacitance injection into the auxiliary winding of the machine, which is electrically isolated from the main winding but magnetically coupled to it. It is shown that by proper tuning of the injected capacitance, the torque and output power of the machine is markedly enhanced at improved power factor. With the enhanced output power achievable by capacitance injection, the transfer field machine can compare favorably with an equivalent induction motor except that the synchronous speed is inherently limited to half the frequency of the stator $\mathrm{mmf}$ wave $\left(\omega_{r}=1 / 2 \omega_{0}\right)$
\end{abstract}

Keywords: capacitance injection, enhanced output power, electrically isolated winding, transfer-field machine.

\subsection{INTRODUCTION}

The transfer-field (TF) machine in its most elementary form comprises two identical salient-pole machines whose rotors are mechanically coupled together but with their pole axes displaced by $1 / 2 \pi$ electrical radians in space. This class of machine was first reported by Schenfer [1]. Each unit machine comprising the TF machine has two sets of windings known as the main and auxiliary windings respectively. The main winding are interconnected in series and connected to the utility supply while the auxiliary windings are transposed in passing from one unit machine to the other and short-circuited. The machine is brushless and there are no windings on the rotor, including damper windings, the main and auxiliary windings being located on the stator side only. The machine is self-starting and the torque-slip curve is similar to that of a poly-phase induction motor operating at half synchronous speed as reported in [2] and [3]. Analogously to an induction motor, the relationship between the frequency of the current in the main and auxiliary windings is $\omega_{0}:(2 s-1) \omega_{0}$. From the on-set of analysis, the paper by Cathey [5] treated the machine as an induction machine and obtained a single magnetizing reactance from which performance was assessed. The approach adopted in [4] is more straightforward as it considers the inductances of each component machine as a function of rotor position on account of the saliency in the rotor magnetic circuit; this naturally yielded two inductances in the $\mathrm{d}$ - and q-axis. Both approaches produced similar results but it is easier to appreciate the analysis done in [4].

The power output of the TF machine is very low compared to that of an equivalent induction machine on account of high leakage reactance arising from the following:

(a) the slots are deeper in order to accommodate the two sets of windings (main and auxiliary). Deep slots give rise to high slot leakage.

(b) the inter-section conductors between one unit machine and the other in cascade do not contribute to energy conversion but add to the overall leakage reactance of the machine

(c) the end winding leakage is twice the normal endwinding leakage because of the two unit machines in cascade

Equivalent circuit of the TF machine derived from its performance analysis $[4,5]$ shows that the quadrature axis reactance adds up to the leakage reactance of the machine. For these shortcomings, the TF machine has been restricted to laboratories and research attention to it is scanty.

Ijeomah [6] attempted to enhance the output power of the machine by injecting slip frequency voltage of (2s1) $\omega_{0}$ into the auxiliary winding of the machine using semiconductor devices. This technique is akin to that 
of Burbridge and Beattie [7] although they used an auxiliary supply plant.

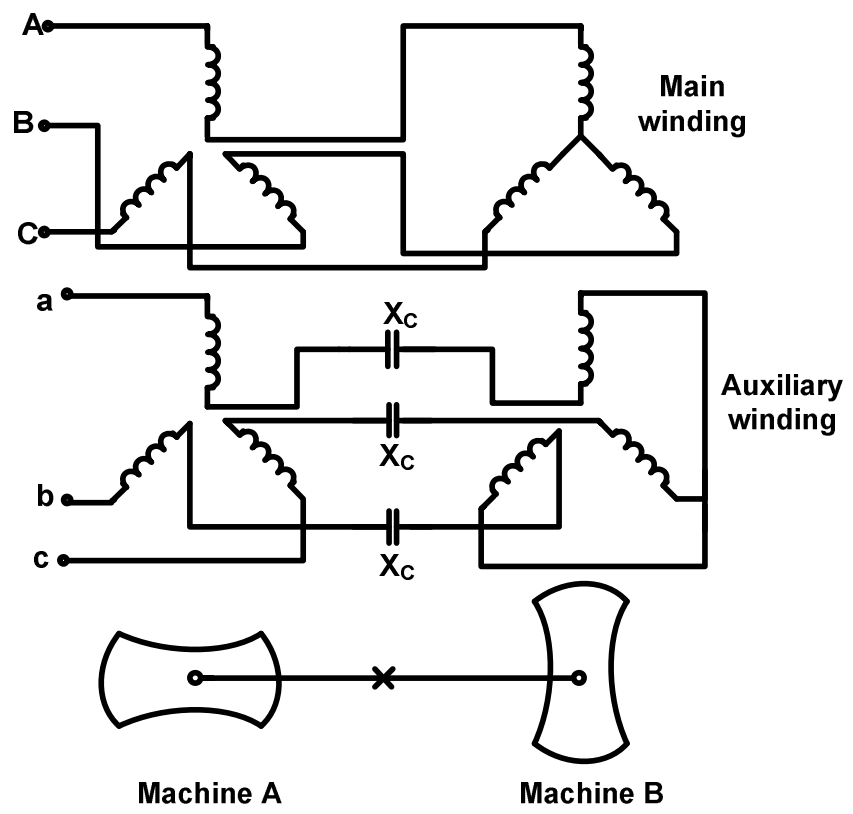

Figure 1: Connection diagram of the capacitor-assisted TF machine

The injected voltage into the auxiliary winding was made to be additive to the one induced into the auxiliary winding from the main winding of the TF machine. Consequently, the auxiliary winding current is boosted, and by transformer action, a corresponding current is drawn by the main winding which is connected to the utility supply; hence increasing the output power of the machine as well as the starting torque.

This paper studies the enhancement of the output power of the machine by direct capacitance injection into the auxiliary winding. By proper capacitance tuning of the injected capacitor, the excessive leakage reactance of the machine is neutralized with consequent increase in output power of the machine and the starting torque at improved power factors. Figure 1 shows the connection scheme of the machine with capacitor now in the auxiliary winding circuit.

\section{MODEL OF THE ENHANCED MACHINE}

To assist an ac machine with a capacitor, an additional winding to which the capacitor is to be connected is necessary just like in single-phase motors. This is because, if the capacitor is connected in series with a single-winding machine, it will reduce the machine reactance, allowing the machine to draw excessive currents and if connected in parallel, it will minimally improve the power factor of the source and not the internal power factor of the machine itself $[8,9]$. A capacitor connected to a second winding can be tuned to obtain the desired machine characteristics while meeting the current carrying capability limit of the windings.

The voltage equations in the $d$ - $q$ rotor reference frame of the classical TF machine were derived [4]. When the auxiliary winding includes capacitors as shown in Figure 1, the main winding equations remain as in (1) - (3) which are the same as reported in [4], but the auxiliary winding voltage equations modify to (4) and (5) on account of the presence of capacitors.

$$
\begin{aligned}
& \mathrm{V}_{\mathrm{Q}}=r \mathrm{i}_{\mathrm{Q}}+\omega \lambda_{\mathrm{D}}+\mathrm{p} \lambda_{\mathrm{Q}} \\
& \mathrm{V}_{\mathrm{D}}=\mathrm{rI}_{\mathrm{Q}}-\omega \lambda_{\mathrm{Q}}+\mathrm{p} \lambda_{\mathrm{D}} \\
& \mathrm{V}_{\mathrm{O}}=\mathrm{rI}_{\mathrm{O}}+\mathrm{p} \lambda_{\mathrm{O}} \\
& \mathrm{V}_{\mathrm{q}}=\mathrm{rI}_{\mathrm{q}}+\left(\omega-2 \omega_{\mathrm{r}}\right) \lambda_{\mathrm{q}}+\mathrm{p} \lambda_{\mathrm{d}}+V_{c q} \\
& \mathrm{~V}_{\mathrm{d}}=\mathrm{rI}_{\mathrm{d}}-\left(\omega-2 \omega_{\mathrm{r}}\right) \lambda_{\mathrm{q}}+\mathrm{p} \lambda_{\mathrm{d}}+V_{c d} \\
& \mathrm{~V}_{\mathrm{O}}=\mathrm{rI}_{\mathrm{o}}+\mathrm{p} \lambda_{\mathrm{o}}
\end{aligned}
$$

The flux linkages are same as derived in [4] and are expressed as:

$$
\begin{aligned}
& \lambda_{\mathrm{Q}}=\left(2 \mathrm{~L}_{\mathrm{L}}+\mathrm{L}_{\mathrm{mq}}+\mathrm{L}_{\mathrm{md}}\right) \mathrm{I}_{\mathrm{Q}}-\left(\mathrm{L}_{\mathrm{md}}-\mathrm{L}_{\mathrm{mq}}\right) \mathrm{I}_{\mathrm{q}} \\
& \lambda_{\mathrm{D}}=\left(2 \mathrm{~L}_{\mathrm{L}}+\mathrm{L}_{\mathrm{mq}}+\mathrm{L}_{\mathrm{md}}\right) \mathrm{I}_{\mathrm{D}}+\left(\mathrm{L}_{\mathrm{md}}-\mathrm{L}_{\mathrm{mq}}\right) \mathrm{I}_{\mathrm{d}} \\
& \lambda_{\mathrm{O}}=2 \mathrm{~L}_{\mathrm{L}} \mathrm{I}_{\mathrm{O}} \\
& \lambda_{\mathrm{q}}=\left(2 \mathrm{~L}_{\mathrm{L}}+\mathrm{L}_{\mathrm{mq}}+\mathrm{L}_{\mathrm{md}}\right) \mathrm{I}_{\mathrm{q}}-\left(\mathrm{L}_{\mathrm{md}}-\mathrm{L}_{\mathrm{mq}}\right) \mathrm{I}_{\mathrm{Q}} \\
& \lambda_{\mathrm{d}}=\left(2 \mathrm{~L}_{\mathrm{L}}+\mathrm{L}_{\mathrm{mq}}+\mathrm{L}_{\mathrm{md}}\right) \mathrm{I}_{\mathrm{d}}+\left(\mathrm{L}_{\mathrm{md}}-\mathrm{L}_{\mathrm{mq}}\right) \mathrm{I}_{\mathrm{d}} \\
& \lambda_{\mathrm{o}}=2 \mathrm{~L}_{\mathrm{L}} \mathrm{I}_{\mathrm{o}}
\end{aligned}
$$

and $\mathrm{R}$ is sum of the resistances of the main or auxiliary windings in both machine halves. The following equations define the capacitor voltages (also in the rotor reference frame) appearing in (4) and (5):

$$
\begin{aligned}
& \mathrm{pV}_{\mathrm{cd}}=\frac{\mathrm{I}_{\mathrm{d}}}{\mathrm{C}}+\left(\omega-2 \omega_{\mathrm{r}}\right) \mathrm{V}_{\mathrm{cq}} \\
& \mathrm{pV}_{\mathrm{cq}}=\frac{\mathrm{I}_{\mathrm{q}}}{\mathrm{C}}-\left(\omega-2 \omega_{\mathrm{r}}\right) \mathrm{V}_{\mathrm{cd}}
\end{aligned}
$$

The torque and mechanical equations are:

$$
\begin{aligned}
& \mathrm{T}_{\mathrm{e}}=\frac{3}{4} \mathrm{p}_{\mathrm{r}}\left(\mathrm{L}_{\mathrm{md}}-\mathrm{L}_{\mathrm{mq}}\right)\left(\mathrm{I}_{\mathrm{Q}} \mathrm{I}_{\mathrm{d}}+\mathrm{I}_{\mathrm{q}} \mathrm{I}_{\mathrm{D}}\right) \\
& \frac{\mathrm{J}}{\mathrm{p}_{\mathrm{r}}} \frac{\mathrm{d} \omega_{\mathrm{r}}}{\mathrm{dt}}=\mathrm{T}_{\mathrm{e}}-\mathrm{T}_{\mathrm{L}}
\end{aligned}
$$

where $\mathrm{p}_{\mathrm{r}}$ is the number of poles and $\mathrm{T}_{\mathrm{L}}$ is the motor shaft load torque.

\section{STEADY-STATE ANALYSIS}

In the analysis presented in this section, the performance of the conventional TF machine is closely compared with the capacitor-assisted machine for different capacitive reactance values. For brevity in 
the plots, only two capacitive reactance values are taken for analysis and experimentation but it should be understood that various values can be used so long as the current supported by both the main and auxiliary windings do not exceed rated values. The parameters of the machine used for this study shown in Table I.

Table I: Parameters of the experimental machine [4]

\begin{tabular}{ll}
\hline Parameter & Value \\
\hline $\mathrm{L}_{\mathrm{md}}(\mathrm{mH})$ & 133.3 \\
$\mathrm{~L}_{\mathrm{mq}}(\mathrm{mH})$ & 25.6 \\
$\mathrm{~L}_{\mathrm{ls}}(\mathrm{mH})$ & 6.0 \\
$\mathrm{r}_{\mathrm{A}}=\mathrm{r}_{\mathrm{a}}=1 / 2 \mathrm{r}(\Omega)$ & 3.0 \\
$\mathrm{~V}(V)$ & 220 \\
\hline
\end{tabular}

\subsection{The per-phase equivalent circuit}

The per-phase steady-state equivalent circuit of the conventional machine has been derived also in [4] without the capacitor and is shown in Figure2a. With a capacitor now connected to the auxiliary winding, the equivalent circuit now modifies to Figure $2 b$. Capacitive reactance is well known to be $x_{c}=\frac{1}{j \omega C}$ where $\omega$ is the operating angular frequency. Since the frequency of current in the auxiliary winding is $(2 \mathrm{~s}-$ 1) $\omega$, the capacitive reactance becomes $\frac{1}{j(2 s-1) \omega C}=\frac{-j x_{c}}{2 s-1}$. It therefore follows that the KVL equation for the auxiliary winding circuit is given by:

$$
\begin{aligned}
\frac{j x_{c} I_{a}}{2 s-1}= & \left(r+j 2 x_{q}(2 s-1)\right) I_{a} \\
& +j\left(x_{m d}-x_{m q}\right)(2 s-1)\left(I_{A}+I_{a}\right)
\end{aligned}
$$

Dividing through by $(2 \mathrm{~s}-1)$,

$$
\begin{aligned}
\frac{j x_{c} I_{a}}{(2 s-1)^{2}} & =\left(\frac{r}{2 s-1}+j 2 x_{q}\right) I_{a} \\
& +j\left(x_{m d}-x_{m q}\right)\left(I_{A}+I_{a}\right)
\end{aligned}
$$

It is now observed that the capacitor is not represented by $-\mathrm{j} x_{\mathrm{c}}$ but by $\frac{-j x_{c}}{(2 s-1)^{2}}$ on account of the frequency of the auxiliary winding differing from that of the main winding.

From the equivalent circuit of Figure $2 b$, it is seen that the leakage reactance is twice the sum of the normal per phase winding leakage plus the quadrature axis magnetizing reactance, i.e. $2 x_{\mathrm{q}}=2\left(x_{I_{\mathrm{s}}}+x_{\mathrm{mq}}\right)$. The torque producing component of the reactances is $\left(X_{\mathrm{md}}-X_{\mathrm{mq}}\right)$ just like in reluctance machines. It can then be inferred that a reduced quadrature axis reactance leads to lower leakage reactance and higher torque. There is, however, a limit to how low the quadrature axis reactance can be reduced by rotor design [10]. Therefore a reduction of the leakage reactance in the auxiliary winding can be accomplished by choosing an appropriate value of $\mathrm{X}_{\mathrm{C}}$.

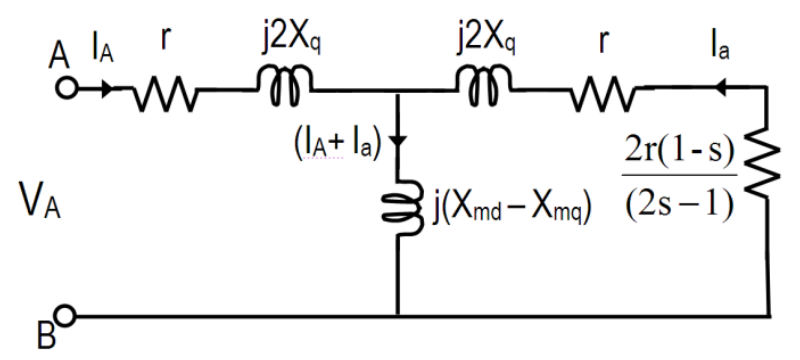

(a)

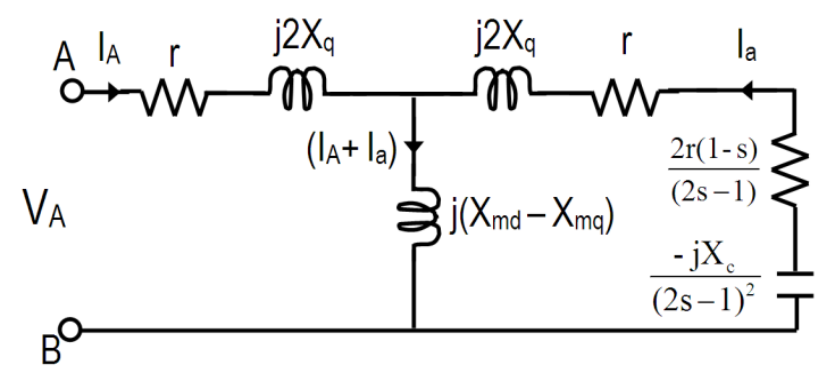

(b)

Figure 2: Equivalent circuit of the transfer-field machine (a) without capacitor, (b) with capacitor connected to the auxiliary winding.

\subsection{Input impedance}

The machine input impedance looking through the terminals A-B of Figure $2 b$ can be readily written as:

$$
Z=r+j 2 X_{q}+\frac{j X_{D}\left(j 2 X_{q}+\frac{r}{2 s-1}-\frac{j x_{c}}{(2 s-1)^{2}}\right)}{j X_{D}+j 2 X_{q}+\frac{r}{2 s-1}-\frac{j x_{c}}{(2 s-1)^{2}}}
$$

where $x_{\mathrm{D}}=x_{\mathrm{md}}-x_{\mathrm{mq}}$

Equation (19) can be resolved into real $\operatorname{Re}(\mathrm{Z})$ and imaginary $\operatorname{Im}(Z)$ parts from which other performance indices can be assessed.

\subsection{Power factor}

The power factor of the TF machine is given by:

$$
\cos \phi=\frac{\operatorname{Re}(Z)}{\sqrt{(\operatorname{Re}(Z))^{2}+(\operatorname{Im}(Z))^{2}}}
$$

For different capacitor values, the power factor is shown in Figure 3. It is remarkable to see that the power factor of the capacitor-assisted $\mathrm{TF}$ machine is now many times higher than that of the conventional TF machine for a range of slip values.

To establish a condition for unity power factor the imaginary part of (19) was set to zero and solved for 
$x_{c}$. This yielded a quadratic function in $x_{c}$ which resolves to two solution given as:

$x_{c_{-} u p f}=\left(s-\frac{1}{2}\right)\left(\begin{array}{l}2 x_{D} s+16 x_{q}-x_{D}-8 x_{q} \\ \pm \sqrt{\left.x_{D}^{2}\left(4 s^{2}-4 s+1\right)-4 r^{2}\right)}\end{array}\right)$

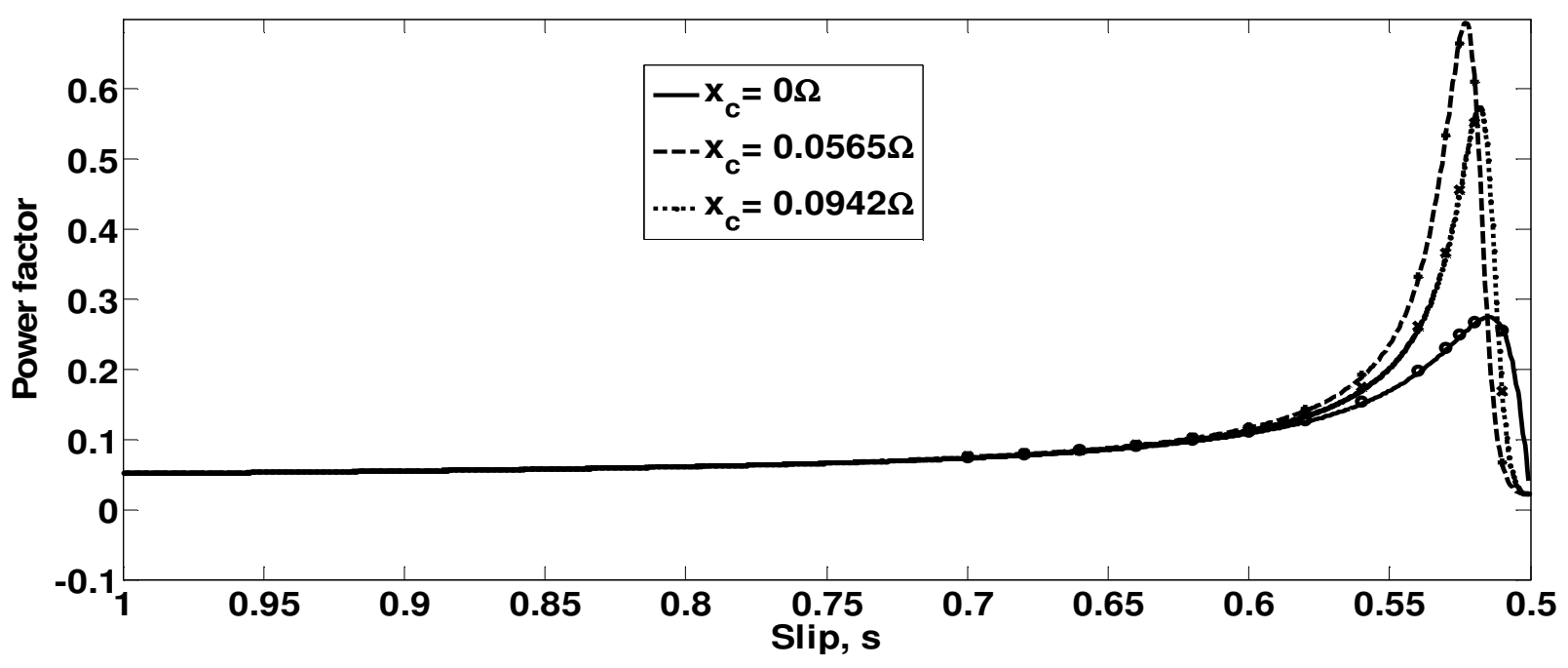

Figure3: Power factor

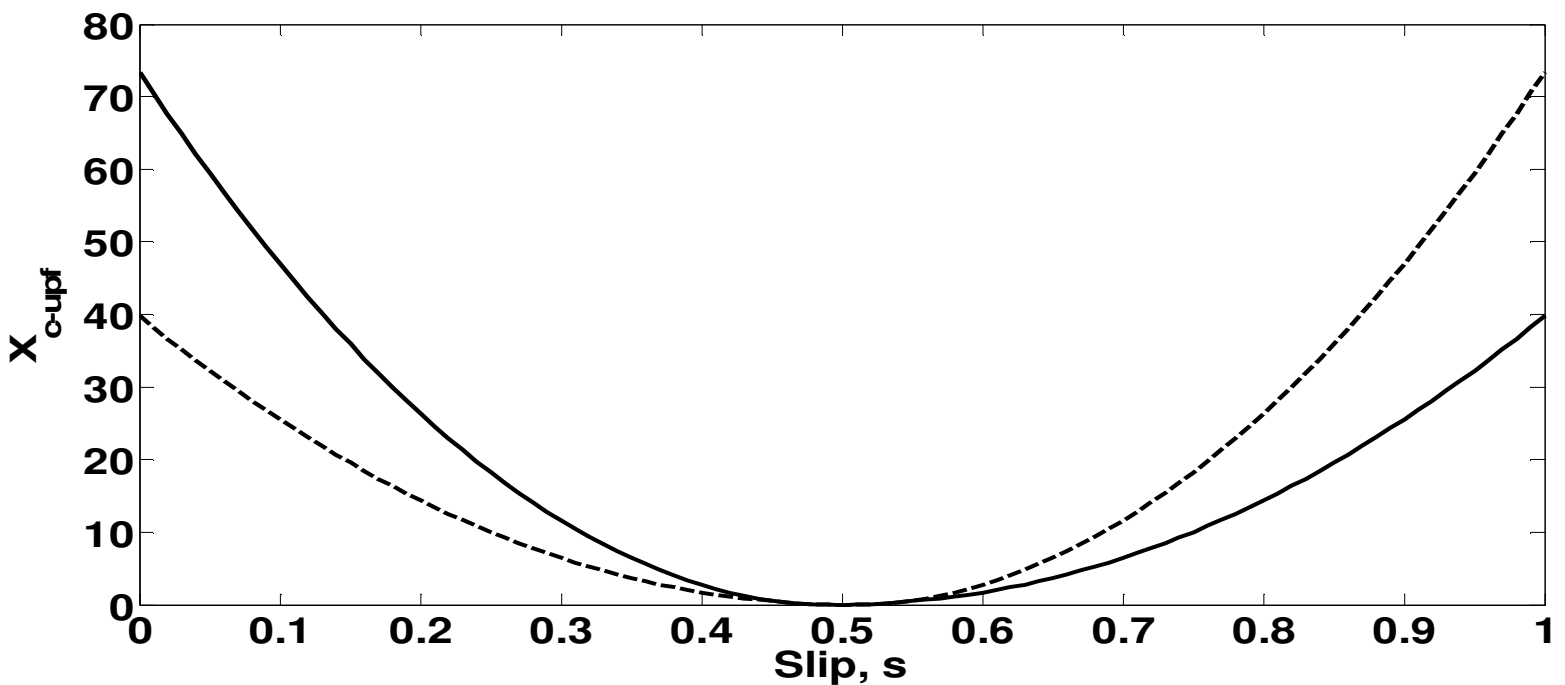

Fig 4: Capacitance value for unity power factor operation.

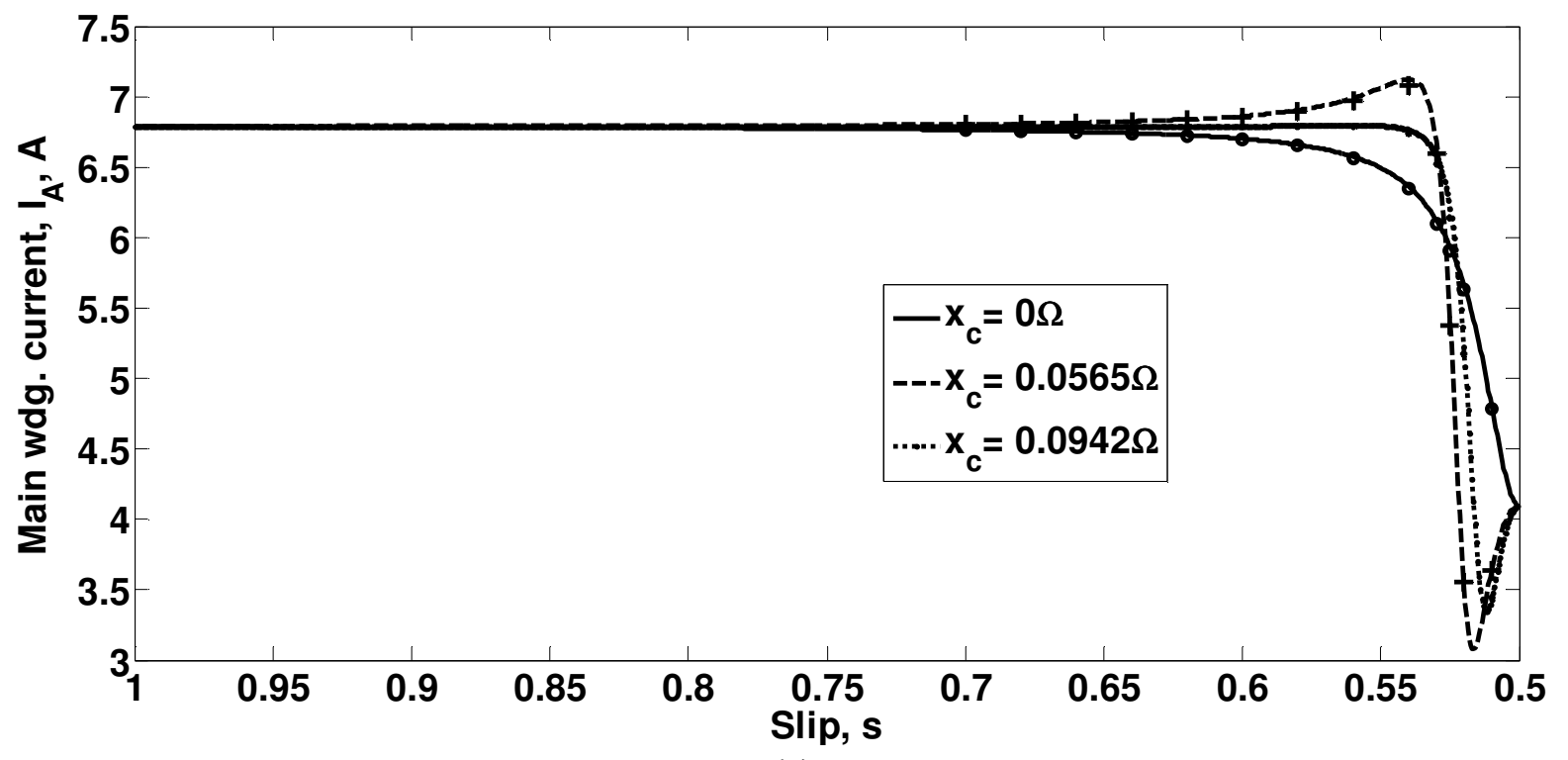

(a) 


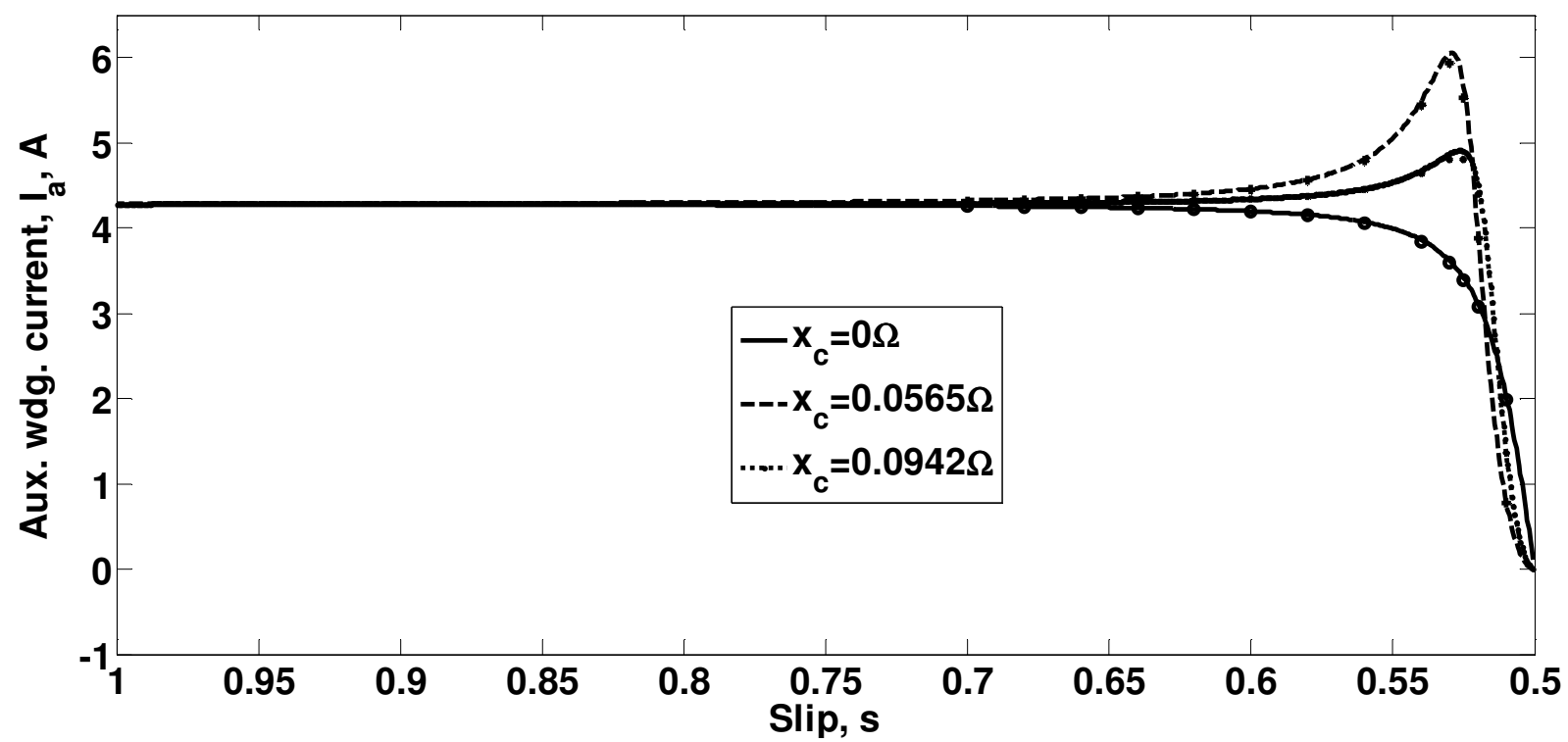

(b)

Figure 5: Main and auxiliary winding currents

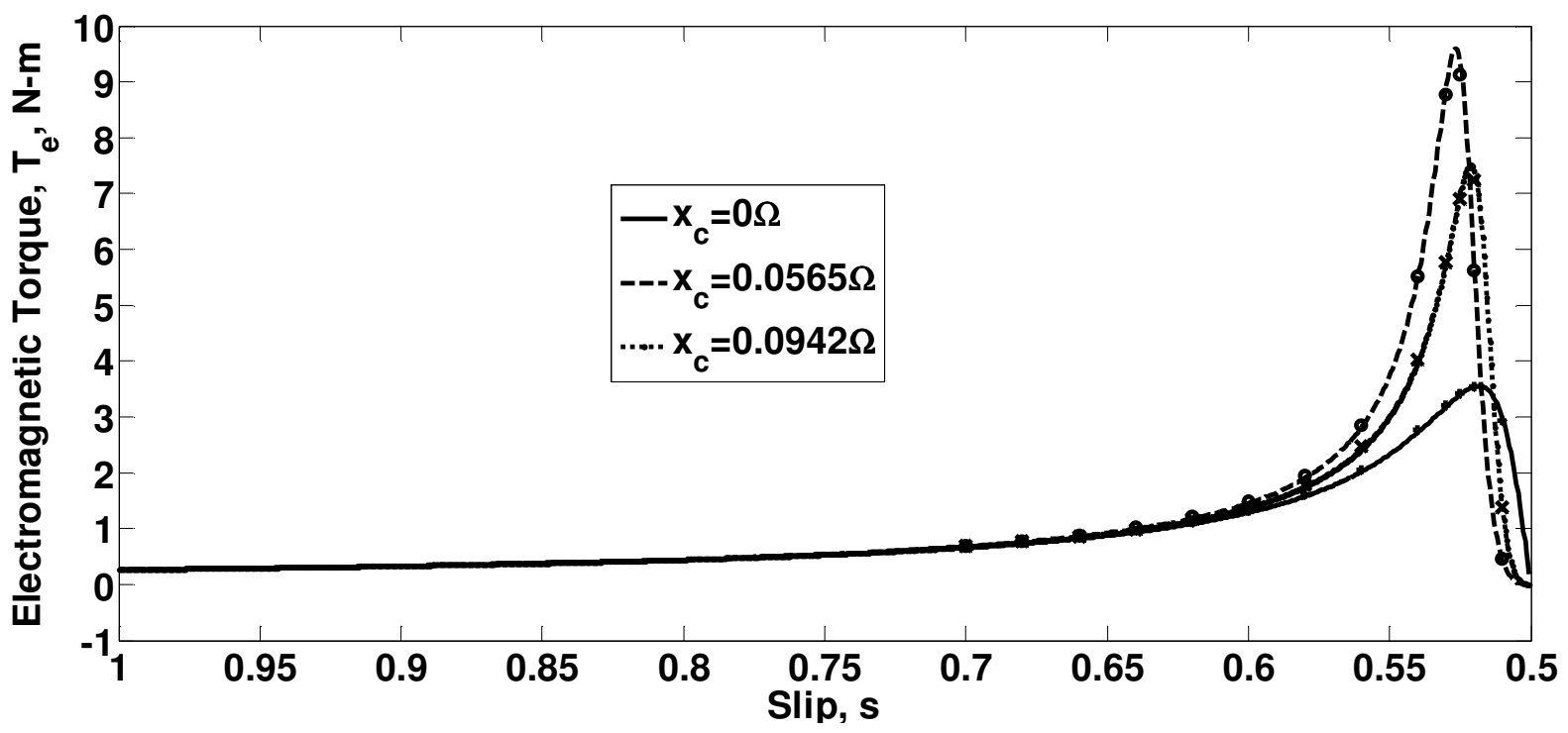

Figure 6: Torque vs slip

The unity power factor operation curves (Figure4), show that both conditions depend on slip values so it is not possible to choose a capacitor value that will satisfy this condition at all slip ranges. Choice of capacitor values has to be carefully determined because as will be seen shortly, high capacitive reactance values will make the machine draw intolerably high currents.

\subsection{Main and auxiliary winding currents}

The main and auxiliary winding currents can be easily calculated from the equivalent circuit of Figure $2 b$ as follows:

$I_{A}=\frac{V}{Z}$ and $I_{a}=\frac{-Z_{2}}{Z_{2}+Z_{3}} I_{A}$

where:

$$
\begin{aligned}
& Z_{2}=j\left(x_{m d}-x_{m q}\right) \text { and } \\
& Z_{3}=r+\frac{2 r(1-s)}{(2 s-1)}+j\left(2 x_{q}-\frac{x_{c}}{(2 s-1)^{2}}\right)
\end{aligned}
$$

The currents $I_{A}$ and $I_{a}$ for differing values of $x_{c}$ with slip as parameter are shown in Figure 5.

\subsection{Torque}

The steady-state electromagnetic torque of the capacitor-assisted $\mathrm{TF}$ machine can be shown by conventional reference frame theory [6] to be:

Manipulation of (24) yields:

$$
\mathrm{T}_{\mathrm{e}}=3 \frac{\left|\mathrm{I}_{\mathrm{a}}\right|^{2}}{\omega_{\mathrm{r}}} 2 \mathrm{r}\left(\frac{1-\mathrm{s}}{2 \mathrm{~s}-1}\right)=\frac{6\left|\mathrm{I}_{\mathrm{a}}\right|^{2} \mathrm{r}}{\omega(2 \mathrm{~s}-1)}
$$




\section{EMPIRICAL VALIDATION}

Performance calculations presented in the previous section was verified experimentally using two identical three-phase 2-pole prototype laboratory machines. The test arrangement was to couple the two machines mechanically with the axes of the rotors displaced by $90^{\circ}$ with respect to each other. Ac capacitors were placed in the auxiliary winding circuit as shown in Figure 1. The overall set up was energized with a variable-voltage constant frequency source and measurements of main and auxiliary winding currents, speed and torque were recorded for every loading of the machine. A dc generator coupled to the machine set and supplying a rheostat was used as the load. The slip was then calculated from values of measured rotor speed and plotted with measured torque. A picture of the experimental set up is shown in Figure 7.For a particular value of load, different values of capacitive reactance were switched on and variables measured before the load is changed.

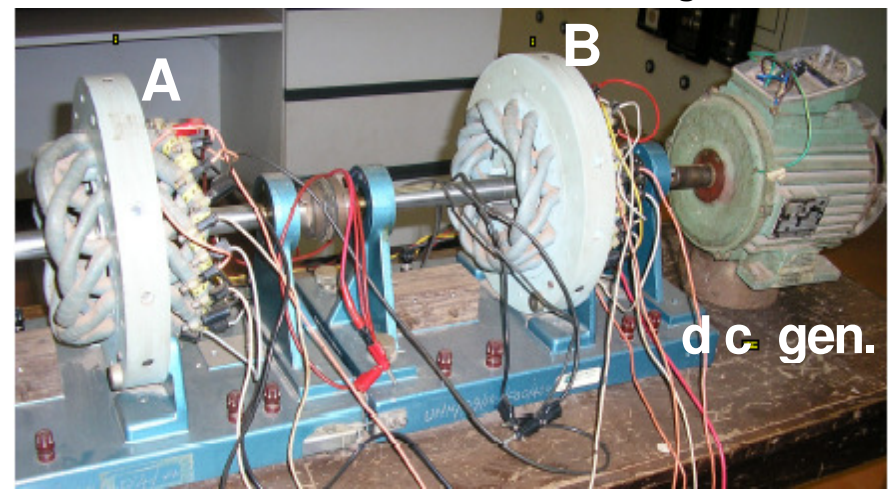

Figure Z: Picture of the experimental machine

\section{DISCUSSION OF RESULTS AND CONCLUSIONS}

All the results are to a great extent in line with the calculations. In all the plots shown, $x_{c}=0$ represents the conventional operation in which the auxiliary winding is short-circuited without connecting a capacitor. The starting current (current at slip $=1$ ) is not influenced by the capacitive reactance for both main and auxiliary windings. In fact it is evident that merely short-circuiting the auxiliary winding leads to poorer performance than connecting a capacitive reactance to it. There is more agreement in main winding current than in the auxiliary winding current. There is an increase in current in both main and auxiliary windings around slip values of 0.51 and 0.55 and this is the region in which the machine is usually operated for stability reasons. A common feature in all the results is that an enhanced output torque also results in an enhanced power factor and these are attended by increased current on the windings. The scheme, however, allows for adjustment of machine effective reactance to extract better performance within the rated current range. The improvement in power factor and torque are very remarkable. Much higher values cannot be obtained in practice because of current loadings on the windings. The scheme reported here is, to the best of the knowledge of the authors, an improvement on the existing performance of transfer field electric machines.

\section{REFERENCES}

[1] Schenfer C. "Synchronous-Induction motor with excitation on the stator side" (in German), Electrotech. \& Maschinenebau 1926; 44:345-348.

[2] Broadway ARW, Tan SCF. "Brushless stator-controlled synchronous induction machine", Proc IEE 1973; 120:860-866.

[3] Agu L. A. "The transfer-field machine", Electric machines and Electromechanics, pp. 403-418. 1978.

[4] Anih, L. U. and Obe, E.S., "Performance Analysis of a Composite Dual-Winding Reluctance Machine", Energy Conversion and Management, Vol. 50, pp. 3056-3062, 2009.

[5] Cathey, J. J. and Nasar, A. A, "Equivalent circuit of transfer field machine for asynchronous mode of operation" Electric machines and Electromechanics, Vol. 6, pp.307-321, 1983.

[6] Ijeomah, C. N. "Torque enhancement of a reluctance effect machine by slip-frequency secondary voltage injection method", Masters degree thesis, Department of Electrical Engineering, University of Nigeria, Nsukka, January 1994.

[7] Burbidge, R. F. and Beattie, W. C., "Doubly-fed operation of Cascade connected Machines", Proc. I.E.E. Nov. 1967, Vol. 114, pp 1657-64.

[8] Obe, E. S. and Senjyu, T, "Analysis of a Polyphase Synchronous Reluctance Motor with Two Identical Stator Windings" Electric Power Systems Research (EPSR). Vol. 76, Nos. 6-7, pp. 515-524, 2006.

[9] Obe, E. S. "Steady-state performance of a synchronous reluctance motor with capacitive assistance" Electric Power Systems Research, Vol. 80, No. 10, pp.12401246, 2010.

[10] Staton, D. A., Miller, T.J.E., and Wood, S.E., "Maximizing the saliency ratio of the synchronous reluctance motor", IEE Proc. pt-B Electric Power Appl. 140 (4), pp.249259, 1993. 